\title{
Correction to: Feasibility of identifying important changes in care management resulting from cardiovascular magnetic resonance (CMR) using hospital episode data in patients who activate the primary percutaneous coronary intervention (PPCl) pathway
}

Maria Pufulete ${ }^{1 *}$, Jessica Harris ${ }^{1}$, Stephen Dorman², Lynn Cook ${ }^{3}$, Chiara Bucciarelli-Ducci ${ }^{2}$, John P. Greenwood ${ }^{4}$, Richard Anderson ${ }^{5}$, Rachel Brierley ${ }^{1}$ and Barnaby C. Reeves ${ }^{1}$

Correction to: BMC Med Res Methodol (2019) 19:116

https://doi.org/10.1186/s12874-019-0755-3

In the original publication of this article [1], the author noted two corrections after publication.

1. There is a middle initial in John P. Greenwood.

2. An institution's name in the Funding section should be changed from "NIHR Bristol Biomedical Research Unit for Cardiovascular Disease" to "NIHR Bristol Biomedical Research Centre".

The original article has been corrected.

The authors apologize for the inconvenience caused to our readers.

\section{Author details}

${ }^{1}$ Clinical Trials and Evaluation Unit, University of Bristol, Level 7, Bristol Royal Infirmary, Queen's Building, Bristol, UK. ${ }^{2} \mathrm{NIHR}$ Bristol Cardiovascular Research Unit, Bristol Heart Institute, University of Bristol, Bristol, UK. ${ }^{3}$ Department of Information Management and Technology, University Hospitals Bristol NHS Foundation Trust, Bristol, UK. ${ }^{4}$ Multidisciplinary Cardiovascular Research Centre and Leeds Institute of Cardiovascular and Metabolic Medicine, University of Leeds, Leeds, UK. ${ }^{5}$ University Hospitals of Wales, Heath Park, Cardiff, UK.
Published online: 15 October 2019

\section{Reference}

1. Pufulete $\mathrm{M}$, et al. Feasibility of identifying important changes in care management resulting from cardiovascular magnetic resonance (CMR) using hospital episode data in patients who activate the primary percutaneous coronary intervention (PPCl) pathway. BMC Med Res Methodol. 2019;19:116

* Correspondence: maria.pufulete@bristol.ac.uk

${ }^{1}$ Clinical Trials and Evaluation Unit, University of Bristol, Level 7, Bristol Royal Infirmary, Queen's Building, Bristol, UK

Full list of author information is available at the end of the article

(c) The Author(s). 2019 Open Access This article is distributed under the terms of the Creative Commons Attribution 4.0 International License (http://creativecommons.org/licenses/by/4.0/), which permits unrestricted use, distribution, and reproduction in any medium, provided you give appropriate credit to the original author(s) and the source, provide a link to the Creative Commons license, and indicate if changes were made. The Creative Commons Public Domain Dedication waiver (http://creativecommons.org/publicdomain/zero/1.0/) applies to the data made available in this article, unless otherwise stated. 